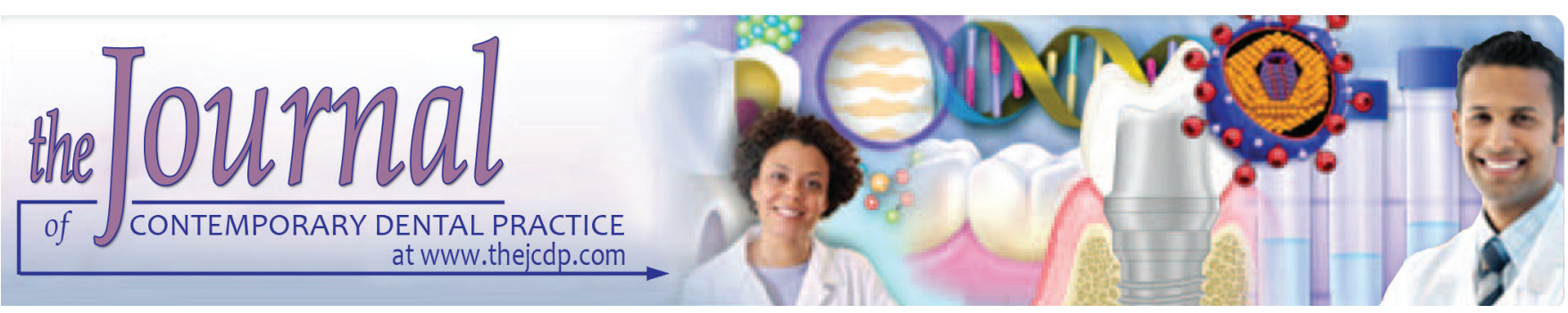

\title{
In vitro Evaluation and Comparison of Microleakage of Two Restorative Composite Resins in Class II Situations using Confocal Laser Scanning Microscopy
}

1Bibhu D Nanda, ${ }^{2}$ Pallavi Sharma, ${ }^{3}$ Munmun Moudgil, ${ }^{4}$ Vikas Sharma, ${ }^{5}$ Ajay K Gupta, ${ }^{6}$ Dhruv Gupta

\begin{abstract}
Aim: The placement of composite in teeth is not an easy task and it poses many challenges. Microleakage is one of the factors that affects the success of any composite restoration. It influences the longevity of dental restorations. The present study was aimed to evaluate and compare microleakage of two restorative composites resins in class II cavities using confocal laser scanning microscopy (CLSM).
\end{abstract}

Materials and methods: This was an in vitro study, which included 20 permanent mandibular first molar. On each tooth, 40 class II cavities were prepared with a carbide bur. The teeth were then randomly divided into two groups of 10 each. Group I included teeth in which SonicFill Bulk Fill composite was used. Group II included teeth in which Tetric EvoCeram Bulk Fill composite was used. The microleakage was measured using confocal microscopy at $10 \times$ magnification in the fluorescent mode by a scoring system.

Results: Estimation was done at cervical and occlusal levels, wherein group I included 10 teeth which were restored with SonicFill Bulk Fill composite and group II included 10 teeth which were restored with Tetric EvoCeram Bulk Fill composite. Microleakage was quantified on scoring basis, which was consecutively based on the dye penetration at different levels. Data thus obtained statistically revealed that microleakage was

${ }^{1}$ Dr. Bibhu Dutt Nanda Dental Touch Clinic, Greater Noida Uttar Pradesh, India

2"My dentist", Hercules, California, USA

${ }^{3,4}$ Late Smt. Mansa Devi Dental Wing (Kalia Nursing Home) Hoshiarpur, Punjab, India

${ }^{5}$ Department of Orthodontics and Dentofacial Orthopedics Shree Bankey Bihari Dental College and Research Centre Ghaziabad, Uttar Pradesh, India

${ }^{6}$ Department of Conservative Dentistry and Endodontics, Faculty of Dental Sciences, King George's Medical University, Lucknow Uttar Pradesh, India

Corresponding Author: Bibhu D Nanda, Dr. Bibhu Dutt Nanda Dental Touch Clinic, Greater Noida, Uttar Pradesh, India, Phone: +919439978379, e-mail: bibhuduttnanda@yahoo.co.in comparatively more in group II as compared with group I. In addition, it was somewhat similar on both cervical as well as occlusal regions. The difference was significant $(p=0.05)$. Comparison was also done at cervical and occlusal levels using Wilcoxon signedrank test, which showed significant levels of differences $(p>0.05)$.

Conclusion: There is more microleakage in Tetric EvoCeram Bulk Fill composite as compared with SonicFill Bulk Fill composite.

Clinical significance: No material seems to totally eliminate microleakage in class II situations with gingival margin ended in dentine. However, CLSM is a useful tool in microleakage evaluation that could be used successfully to estimate the severity of microbial penetrations and material of choice as well.

Keywords: Confocal laser scanning microscopy, Microleakage, Rhodamine B, SonicFill Bulk Fill composite, Tetric EvoCeram Bulk Fill composite.

How to cite this article: Nanda BD, Sharma P, Moudgil M, Sharma V, Gupta AK, Gupta D. In vitro Evaluation and Comparison of Microleakage of Two Restorative Composite Resins in Class II Situations using Confocal Laser Scanning Microscopy. J Contemp Dent Pract 2018;19(9):1100-1104.

Source of support: Nil

Conflict of interest: None

\section{INTRODUCTION}

Dental composite resins are restorative material or adhesive types of synthetic resins. They are most commonly composed of bisphenol A-glycidyl methacrylate and other dimethacrylate monomers, a filler material, such as silica, and a photo-initiator. Since the advent of dental composite resins in the 1960s, they have been made superior through research and development refinement with mean particle sizes of 0.6 to $0.7 \mu \mathrm{m} .{ }^{1}$ The placement of composite in teeth is not an easy task and it poses many challenges. It is time-consuming, lightcuring each increment, and the operator time is required for separate etching, priming, and bonding techniques, especially in class II mesial-occlusal-distal restorations 
and class III cavities. ${ }^{2}$ It has advantages, such as esthetics, more conservative procedure, versatility, reparability, lack of corrosion, insensitive to dehydration, easy to manipulate, reasonably inexpensive, micro-mechanical bonding with tooth structure, etc. Although it has good physical properties, the drawbacks are still there, which is literally challenging for the dentist. Among limitations, polymerization shrinkage and polymerization stress are major. Both result in internal microcracks within the bulk of the material, marginal microleakage and the postoperative sensitivity, disjointing of the bonding agent from the cavity wall with resulting gap formation, shrinkage, enamel microcracks, marginal staining, secondary caries, chipping, discoloration, and lower fracture resistance. ${ }^{3}$ Microleakage is one of the factors that affects the success of any composite restoration. It influences the longevity of dental restorations. An oblique layering technique with increments or cavity designs with a low C-factor can decrease the polymerization shrinkage and microleakage. Bulk Fill composites with enhanced flowability to achieve consistent adaptation to the cavity preparation, elasticity, and low polymerization shrinkage stress reduce microleakage, postoperative sensitivity, and secondary caries. In the literature, most microleakage-related studies had used ordinary low-resolution optical microscope using fluorescent dyes as they present extremely visible and strong color. ${ }^{4}$ Nevertheless, with the usage of CLSM, microleakage examination starts to depend on the fluorescence criteria of the dye other than the color. It is beneficial over conventional microscopy as it offers numerous other advantages like the ability to control field depth, removal of background information, and the potential to assemble serial optical sections even from bulkier samples. With innovation of the SonicFill (Kerr Corp., USA), a combined benefit of low-viscosity composite and a common composite is achieved. Sonic energy is used for activating the composite, leading to fill the cavity and adapt the low-viscosity material easily, and then compact and mold it while the composite changes its consistency till the time it reaches a relative higher viscosity. Some other prominent benefits with this technique are reduced working time and polymerization shrinkage. ${ }^{5}$ The present in vitro experimental study was conducted to evaluate and compare microleakage of two commercially available restorative composites resins in class II cavities using CLSM.

\section{MATERIALS AND METHODS}

This in vitro study included 20 permanent mandibular first molars with no crack, fracture, previous restorations, and no periodontal compromised teeth. Teeth were collected and stored in normal saline. Ethical clearance was taken prior to the execution of study. Class II cavities usually involve occlusal and proximal surfaces of premolars and molars. Forty class II cavities were prepared with a carbide bur, which was in turn discarded after every five preparations. The dimensional extensions of cavity were kept in a way to show $2 \times 3 \mathrm{~mm}$ occlusal and proximal extension with gingival seat at cement-enamel junction. Each cavity was uncontaminated by pumice paste and followed by water spray rinse and gently dried. For ensuring complete building up of the proximal wall, every sample tooth was mounted with adjoining teeth for placement of Tofflemire matrix. All the prepared cavity surfaces were completely dried out using oil-free compressed air along with acid etching ( $37 \%$ phosphoric acid for 15 seconds) and then washed and dried. To make sure precise and accurate bondings, Adper single-bond two-bonding agent was used, which was gently dried and cured. The teeth were then randomly divided into two groups of 10 each. Group I included teeth in which SonicFill Bulk Fill composite was used. Group II included teeth in which Tetric EvoCeram Bulk Fill composite was used. The specimens in each group were restored with the corresponding Bulk Fill composite and cured for 20 seconds. All specimens were then subjected to 1,000 thermal cycles at $5^{\circ} \mathrm{C}$ and $55^{\circ} \mathrm{C}$ with a dwell time of 1 minute at each temperature. Every specimen was then protected with two coats of nail varnish, excluding the resin composite restoration and $1 \mathrm{~mm}$ surrounding region. It was then submerged in $0.6 \%$ aqueous Rhodamine B dye for 48 hours. This is the time when the specimens were ready to be sectioned after rinsing. The microleakage was examined by means of confocal microscopy at $10 \times$ magnification in the fluorescent mode (Figs 1 and 2 ). With a digital scale, the width of interface between restoration and tooth surface was calculated. For measurement of microleakage, a scoring

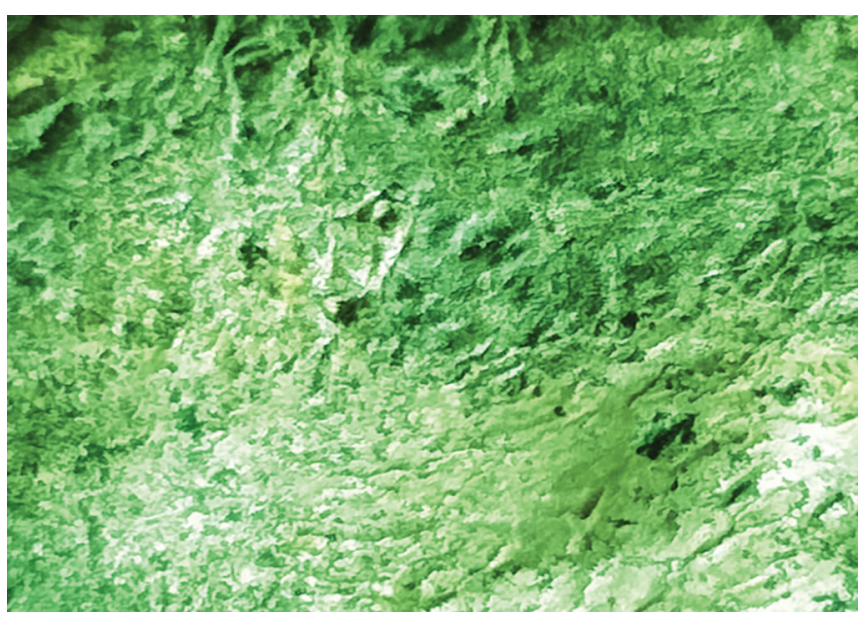

Fig. 1: Confocal microscopic images confirming lesser dye penetration (10× magnification in the fluorescent mode) in group I specimens 


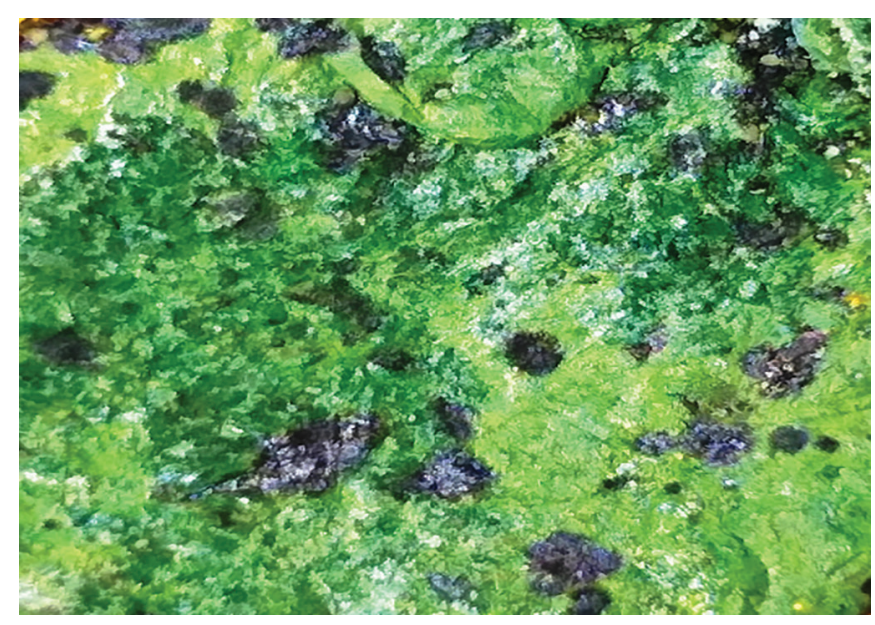

Fig. 2: Confocal microscopic images confirming greater dye penetration (10x magnification in the fluorescent mode) in group II specimens

system given by Radhika et $\mathrm{al}^{6}$ was used as: 0 —no dye penetration; 1 -dye penetration into half extension of the cervical wall; 2 -dye penetration into more than half or complete extension of the cervical wall; 3-dye penetration into the cervical and axial walls toward the pulp.

\section{STATISTICAL ANALYSIS AND RESULTS}

All the observational findings were compiled and sent for statistical evaluation using statistical software Statistical Package for the Social Sciences version 21 (IBM Inc., Armonk, New York, USA). All specimens of two groups were evaluated and compared for microleakage along with occlusal and cervical wall using Kruskal-Wallis

Table 1: Distribution of teeth in groups

\begin{tabular}{|c|c|c|}
\hline \multicolumn{3}{|c|}{ Total 20} \\
\hline Group & $\begin{array}{l}\text { Group I } \\
\text { (SonicFill Bulk Fill } \\
\text { composite) }\end{array}$ & $\begin{array}{l}\text { Group II } \\
\text { (Tetric EvoCeram Bulk Fill } \\
\text { composite) }\end{array}$ \\
\hline Number & 10 & 10 \\
\hline
\end{tabular}

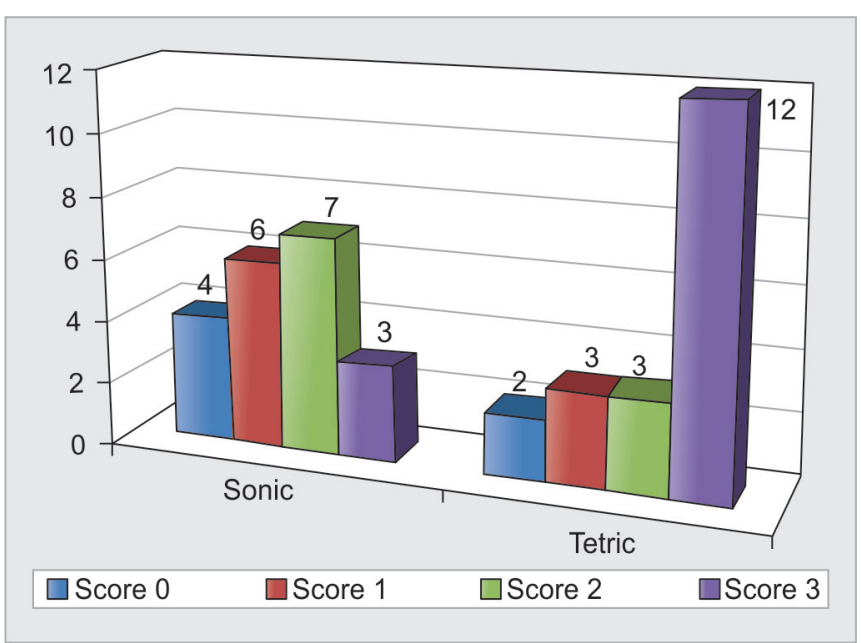

Graph 1: Microleakage among cervical wall test. Table 1 shows that group I included 10 teeth which were restored with SonicFill Bulk Fill composite and group II included 10 teeth which were restored with Tetric EvoCeram Bulk Fill composite. Graph 1 shows cervical region wherein among group I, 4 cavities had score 0,6 had score 1,7 had score 3 , and 3 had score 3 . In case of group II, 2 had score 0,3 had score 1, next 3 had score 2, and 12 had score 3 . Assessment of results shows that microleakage appeared to be comparatively more in group II as compared with group I (Table 2). The difference was significant $(\mathrm{p}=0.05)$. Estimations at occlusal levels revealed that in group I, 5 cavities had score 0,9 had score 1,4 had score 3 , and 2 had score 3 . However, in case of group II, 2 had score 0,4 had score 1, 6 had score 2, and 8 had score 3 (Table 3 and Graph 2). Statistical comparison of mean values was also conducted at cervical and occlusal levels using Wilcoxon signed-rank test, wherein it revealed significant levels of differences ( $p>0.05$, Table 4). Comparative measurement of dye penetration was completed by evaluating intraclass correlation coefficient, which was 0.544 for group I and 0.494 for group II (Table 5).

Table 2: Intergroup comparison at cervical level using Kruskal-Wallis test

\begin{tabular}{|c|c|c|c|c|c|c|}
\hline \multirow[b]{2}{*}{ Group } & \multicolumn{4}{|c|}{ Score } & \multirow[b]{2}{*}{ Mean $\pm S D$} & \multirow[b]{2}{*}{$p$-value } \\
\hline & 0 & 1 & 2 & 3 & & \\
\hline I & 4 & 6 & 7 & 3 & $1.14 \pm 1.25$ & $0.05^{\star}$ \\
\hline II & 2 & 3 & 3 & 12 & $1.83 \pm 1.17$ & \\
\hline
\end{tabular}

*Significant; SD: Standard deviation

Table 3: Intergroup comparison at occlusal level using Kruskal-Wallis test

\begin{tabular}{lllllll}
\hline & \multicolumn{5}{c}{ Score } & \\
\cline { 2 - 5 } Group & 0 & 1 & 2 & 3 & Mean $\pm S D$ & p-value \\
\hline I & 5 & 9 & 4 & 2 & $1.04 \pm 1.54$ & $0.05^{*}$ \\
II & 2 & 4 & 6 & 8 & $1.73 \pm 1.15$ & \\
\hline
\end{tabular}

*Significant; SD: Standard deviation

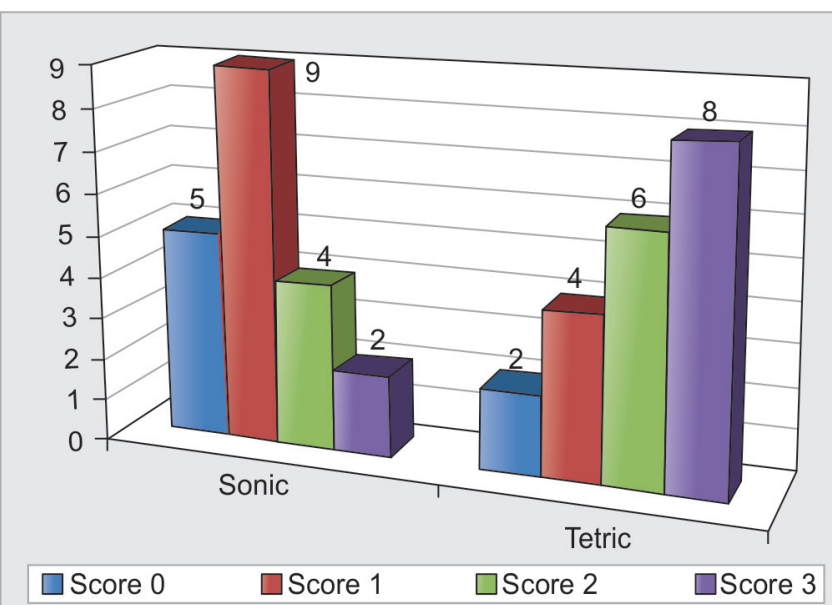

Graph 2: Microleakage among occlusal wall 
Table 4: Wilcoxon signed-rank test for comparative evaluation between occlusal and cervical wall

\begin{tabular}{llll}
\hline Wall in question & Sonic & Tetric & $p$-value \\
\hline Cervical wall & $1.14 \pm 1.25$ & $1.83 \pm 1.17$ & $0.041^{*}$ \\
Occlusal wall & $1.04 \pm 1.54$ & $1.73 \pm 1.15$ & $0.008^{*}$ \\
p-value & $0.005^{*}$ & $0.004^{*}$ & - \\
\hline
\end{tabular}

*Significant

\section{DISCUSSION}

The success of any restoration material depends on marginal integrity. Polymerization shrinkage results in microleakage. In majority of clinical situations, the relative lack of adaptation may possibly occur fairly due to polymerization contraction and excessive temperatures inside the oral cavity. Furthermore, it might sever the adhesion between the adhesive system and the cavity walls forming microgaps. All such kinds of spaces usually permit the infiltration of microorganisms, fluids, and other elements from the intraoral atmosphere along the tooth/restoration junction, which may result in postoperative sensitivity, marginal deterioration, recurrent caries, and pulp injury. ${ }^{7}$ Thus, polymerization shrinkage is the most common cause of failure of composite restorations. Various factors, such as the material's formulation, boundary conditions, and the amount of material in the polymerization reaction affect it. This phenomenon occurs because monomer molecules are converted into a polymer network and hence, exchanges van der Waals spaces into covalent bond spaces, forming tightening stresses in the resin composite leading to microleakage. ${ }^{8}$ The amount of polymerization shrinkage is different for different resin composites. Incremental layering technique has been suggested to reduce this shrinkage. Nowadays, traditional placement techniques for composite resins include this technique. In this study, we compared microleakage of SonicFill Bulk Fill composite resin and Tetric EvoCeram Bulk Fill composite resins in class II cavities using CLSM. In this study, we included class II cavities in 20 mandibular molars. We composed two groups of 10 teeth each. Group I was restored with SonicFill Bulk Fill composite and group II was restored with Tetric EvoCeram Bulk Fill composite. Confocal laser scanning microscopy is a technique used for visualizing subsurface tissue characteristics. The use of lens focuses a few microns beneath the observed surface, avoids the spread of stain due to specimen sectioning, and avoids polishing artifacts too. The focal plane, from which the image is created, is used to see while scattered, reflected, and fluorescent light is eliminated. The laser scanning microscope scans the sample, sequentially point by point, and line by line and assembles the pixel information into one image. ${ }^{9}$ We used a scoring system given by Radhika et al for measuring microleakage. In this study, microleakage was comparatively more in group II as compared with group I. The difference was significant $(p=0.05)$. This is in agreement with the results of Gogna et al, ${ }^{10}$ Helvatjoglu-Antoniades et al, ${ }^{11}$ and Ernst et al. ${ }^{12}$ Furthermore, the comparison results at cervical and occlusal levels showed quite significant outcomes and this was in agreement with the study results of Kleverlaan and Feilzer. ${ }^{13}$ Factors, such as the distance between the lightcuring tip and the resin surface also affect polymerization. If the distance between both is more than $2 \mathrm{~mm}$, the light intensity is significantly reduced. This might prevent adequate polymerization of resin composite materials. ${ }^{14,15}$ Oscillation energy produced by handpiece temporarily increases flowability of resin to attain precise filling of cavities. There is reduced polymerization shrinkage with this technique as the composite resin is placed through a single increment up to $5 \mathrm{~mm} .{ }^{16-20}$ There is drop in viscosity when the sonic energy is applied, which increases the flowability of the composite, enabling quick placement and precise adaptation to the cavity walls. As soon as sonic energy is stopped, the composite returns to a more viscous, nonslumping state that is perfect for carving and contouring. Nevertheless, the results of this in vitro study sought to be compared with other studies of larger sample size. ${ }^{21-25}$ Results of the present study must also be interpreted with caution since in clinical practice the intricate use of latest tooth-colored restorative materials and systems could be limited to the real accessibility and uniformity in terms of clinical outcomes. ${ }^{26-30}$ Further studies are also needed to be conducted to determine the most reliable composites that could offer minimum microleakage with the best possible clinical results.

\section{CONCLUSION}

Within the limitations of the study, it was concluded that microleakage does occur usually in class II restoration, wherein we found it more in Tetric EvoCeram Bulk Fill composite as compared with SonicFill Bulk Fill composite. Other factors, such as material's formulation, boundary conditions, and the amount of material in the polymerization reaction also affect the magnitude of microleakage. Though we have various laboratories or microscopic

Table 5: Measurements of amount of dye penetration

\begin{tabular}{llllll}
\hline & $\begin{array}{l}\text { Mean } \\
\text { Measurement }\end{array}$ & $\begin{array}{l}\text { 95\% confidence interval } \\
\text { differences differences }\end{array}$ & $\begin{array}{l}\text { Independent } \\
\text { t-test }\end{array}$ & $\begin{array}{l}\text { Intraclass correlation } \\
\text { coefficient }\end{array}$ \\
\hline SonicFill Bulk Fill composite & -0.040 & -0.025 (Lower) -0.010 (Upper) & -1.456 & 0.020 & 0.544 \\
Tetric EvoCeram Bulk Fill composite & -0.035 & -0.020 (Lower) -0.005 (Upper) & -1.326 & 0.025 & 0.494 \\
\hline
\end{tabular}


testing methods for restorative systems, we are still lagging in ideal standardization of testing methodologies available. Moreover, our study results could be treated as suggestive for predicting composite for prone situations. However, we expect other large-scale long-term studies to be conducted that could further establish certain concrete guidelines in this field.

\section{CLINICAL SIGNIFICANCE}

In spite of a superfluity of microleakage studies, restoration of class II situations still remains a challenge. Apparently, no material is capable of completely eliminating microleakage, especially from gingival margins of class II cavities. Nevertheless, SonicFill Bulk Fill composite could be considered as the material of choice in class II situations in majority of the clinical scenarios. Confocal local scanning microscopy has also been emerged as a modern way for precise microleakage evaluation, both qualitatively and quantitatively.

\section{REFERENCES}

1. Ben-Amar A, Slutzky H, Matalon S. The influence of 2 condensation techniques on the marginal seal of packable resin composite restorations. Quintessence Int 2007 May;38(5):423-428.

2. Burke FJ, Crisp RJ, James A, Mackenzie L, Pal A, Sands P, Thompson O, Palin WM. Two year clinical evaluation of a low-shrink resin composite material in UK general dental practices. Dent Mater 2011 Jul;27(7):622-630.

3. Hickel R, Manhart J. Longevity of restorations in posterior teeth and reasons for failure. J Adhes Dent 2001 Spring;3(1):45-64.

4. Usha H, Kumari A, Mehta D, Kaiwar A, Jain N. Comparing microleakage and layering methods of silorane-based resin composite in class $\mathrm{V}$ cavities using confocal microscopy: an in vitro study. J Conserv Dent 2011 Apr-Jun;14(2):164-168.

5. Majety KK, Pujar M. In vitro evaluation of microleakage of class II packable composite resin restorations using flowable composite and resin modified glass ionomers as intermediate layers. J Conserv Dent 2011 Oct;14(4):414-417.

6. Radhika M, Sajjan GS, Kumaraswamy BN, Mittal N. Effect of different placement techniques on marginal microleakage of deep class-II cavities restored with two composite resin formulations. J Conserv Dent 2010 Jan;13(1):9-15.

7. Poskus LT, Placido E, Cardoso PE. Influence of adhesive system and placement technique on microleakage of resin-based composite restorations. J Adhes Dent 2004 Autumn;6(3):227-232.

8. Van Ende A, De Munck J, Van Landuyt KL, Poitevin A, Peumans M, Van Meerbeek B. Bulk-filling of high C-factor posterior cavities: Effect on adhesion to cavity-bottom dentin. Dent Mater 2013 Mar;29(3):269-277.

9. Eunice C, Margarida A, João C, Filomena B, Anabela P, Pedro A, Miguel MC, Diana RL, Joana M, Mário P, et al. 99mTc in the evaluation of microleakage of composite resin restorations with Sonic Fill TM. An in vitro experimental model. Open J Stomatol 2012;2:340-347.

10. Gogna R, Jagadis S, Shashikal K. A comparative in vitro study of microleakage by a radioactive isotope and compressive strength of three nanofilled composite resin restorations. J Conserv Dent 2011 Apr-Jun;14(2):128-131.

11. Helvatjoglu-Antoniades M, Kalinderis K, Pedulu L, Papadogiannis $\mathrm{Y}$. The effect of pulse activation on microleakage of a 'packable' composite resin and two "ormocers". J Oral Rehabil 2004;31:1068-1074.

12. Ernst CP, Brandenbusch M, Meyer G, Canbek K, Gottschalk F, Willershausen B. Two-year clinical performance of a nanofiller vs a fine-particle hybrid resin composite. Clin Oral Investig 2006 Jun;10(2):119-125.

13. Kleverlaan CJ, Feilzer AJ. Polymerization shrinkage and contraction stress of dental resin composites. Dent Mater 2005 Dec;21(12):1150-1157.

14. Kidd EA. Microleakage: A review. J Dent 1976 Sep;4(5):199-206.

15. Alani AH, Toh CG. Detection of microleakage around dental restorations: A review. Oper Dent 1997 Jul-Aug;22(4):173-185.

16. Bullard RH, Leinfelder KF, Russel CM. Effect of coefficient of thermal expansion on microleakage. J Am Dent Assoc 1988 Jun;116(7):871-874.

17. Momoi H, Iwase H, Nakano $\mathrm{Y}$, Kohno A, Asanuma A, Yanagisawa K. Gradual increase in marginal leakage of resin composite restorations with thermal stress. J Dent Res 1990 Oct; 69(10):1659-1663.

18. Eick JD, Cobb CM, Chappel P, Spencer P, Robinson SJ. The dentinal structure: Its influence on dentinal adhesion. Part I. Quintessence Int 1991;22:967-977.

19. Deliperi S, Bardwell DN. An alternative method to reduce polymerization shrinkage in direct posterior composite restorations. J Am Dent Assoc 2002 Oct;133(10):1387-1397.

20. Longfellow HW. Resin polymerization. In: Albers HF, editor. Tooth colored restoratives, principles and practices. Hamilton: BC Decker Inc.; 2002. p. 97.

21. Peris AR, Duarte S, de Andrade MF. Evaluation of marginal microleakage in class II cavities: effect of microhybrid, flowable, and compactable resins. Quintessence Int 2003;34:93-97.

22. Fan PL. Resin dentin bonding systems. Council on dental materials, instruments, and equipment. J Am Dent Assoc 1984;108(2):240-241.

23. Estafan D, Estafan A, Leinfelder KF. Cavity wall adaptation of resin based composites lined with flowable composites. Am J Dent 2000 Aug;13(4):192-194.

24. Wahab FK, Shaini FJ. Evaluation of the microleakage at the proximal walls of class II cavities restored using resin composite and precured composite inserts. Quintessence Int 2003 Sep;34(8):600-606.

25. Opdam NJ, Roeters JJ, Peters TC, Burgersdijk RC, Teunis M. Cavity wall adaptation and voids in adhesive class I resin composite restorations. Dent Mater 1996 Jul;12(4):230-235.

26. Hansen EK. Effect of cavity depth and application technique on marginal adaptation of resins in dental cavities. J Dent Res 1986 Nov;65(11):1319-1321.

27. Estafan D, Agosta C. Eliminating microleakage from composite resin system. Gen Dent 2003 Nov-Dec;51(6):506-509.

28. Kemp-Scholte CM, Davidson CL. Complete marginal seal of class $\mathrm{V}$ resin composite restorations effected by increased flexibility. J Dent Res 1990 Jun;69(6):1240-1243.

29. Leevailoj C, Cochran MA, Matis BA, Moore BK, Platt JA. Microleakage of posterior packable resin composites with and without flowable liners. Oper Dent 2001 May-Jun;26(3):302-307.

30. Bayne SC, Thompson JY, Swift Jr EJ, Stamatiades P, Wilkerson M. A characterization of first-generation flowable composites. J Am Dent Assoc 1998 May;129(5):567-577. 